\title{
Prevalence of Schistosomiasis in Warwade Community, Jigawa State, Nigeria
}

\author{
Alhaji, G. K., ${ }^{* 1}$ \& 2 Dogara, M. M., ${ }^{1}$ Balogun, J. B., ${ }^{1}$ Abubakaar, M. M., ${ }^{1}$ Sufi, M. A. ${ }^{1}$, Dawaki, \\ S. S. ${ }^{1}$ and Usman, M. Isah \\ ${ }^{1}$ Department of Biological Sciences, \\ Federal University Dutse, \\ P. M. B. 7156, Dutse, \\ Jigawa State, Nigeria \\ ${ }^{2}$ Department of Science Laboratory Technology, \\ School of Science and Technology, \\ Federal Polytechnic Damaturu, \\ P. M. B. 1006, Damaturu, \\ Yobe State, Nigeria
}

Email: musadogara2013@gmail.com

\begin{abstract}
There is currently no documented literature on the status of transmission of schistosomiasis in Warwade community situated near a dam. This study was designed to determine the prevalence of schistosomiasis in the community. A total of 300 urine and stool samples from randomly selected participants were analysed for S. haematobium and S. mansoni using sedimentation and kato-katz techniques respectively. A pre-tested structured questionnaire was administered to all the participants and in the case of minors their parents/guardians. The data was analysed using Statistical Package for Social Sciences version 25 to determine if there was any significant difference between schistosomiasis and demographic characteristics of participants as well as the association between schistosomiasis and risk factors at $P<0.05$. The results revealed an overall prevalence of $20.3 \%$ with urinary and intestinal schistosomiasis having $12.3 \%$ and $8 \%$ respectively. Out of every 8 persons in the community one had urinary schistosomiasis while in every 12 persons, one had intestinal and in every 5 persons, one had at least either of the species. Urinary schistosomiasis was higher in females, but was the opposite in intestinal infection. Schistosomiasis infection was highest among children $\leq$ 18 years and $\leq 40$ years and the opposite was the case for intestinal schistosomiasis, where 19 to 29 years had the highest prevalence. Age and occupation were the risk factors associated with schistosomiasis infection at $P<0.05$. All the positive samples for urinary schistosomiasis subjected to Polymerase Chain Reaction (PCR) amplification were positive. This study showed that Warwade community is endemic for schistosomiasis.
\end{abstract}

Keywords: Sedimentation, Kato-katz, schistosomiasis, endemic

\section{INTRODUCTION}

Schistosomiasis is the third most devastating tropical disease in the world, being a major public health problem in many developing countries in Africa, south America and the Middle East (Kuntz, 2010).More than 207 million people, $80 \%$ of who live in Africa are infected with schistosomiasis (WHO, 2014). Nigeria is the most endemic country in the 
world for urinary schistosomiasis with an estimated 101.28 million people being at risk and 25.83 million infected (Abbasi et al., 2011).

In Nigeria two species are pathogenic to man, S. haematobium and S. mansoni (Johnsen et al., 2011).The disease caused by S. haematobium is characterized by bloody urine, calcification of the bladder and kidney failure and bladder cancer in adults and is also the major cause of Female Genital Schistosomiasis (FGS) (Butterworth, 1997., Noberg, 2004). On the other hand, intestinal schistosomiasis can result in abdominal pain, diarrhoea and blood in stool. Liver enlargement common in advanced cases, is frequently associated with an accumulation of fluid in the peritoneal cavity, hypertension of the abdominal blood vessels and there may be enlargement of the spleen (WHO, 2020). The prevalence and morbidity of schistosomiasis is highest among fishermen, irrigation workers,farmers, school children, adolescents and young adults (Hotez et al., 2009). Schistosomiasis has negative impact on school performance and the debilitation caused by untreated infection demoralized both social and economic development in endemic areas (Van derwerf et al., 2013).

The global effort to control of schistosomiasis is based on large-scale treatment of at-risk population groups, access to safe water, improved sanitation, hygiene education, and snail control (WHO, 2020). In response to this global effort, Nigeria came up with a national programme to eliminate schistosomiasis together with other Neglected Tropical Diseases (NTDs). According to the Nigeria's master plan for NTDs elimination 2015 - 2020all the 774 Local Government Areas (LGAs) in the country have been mapped, 603 were endemic for schistosomiasis $(\mathrm{FMOH}, 2015)$. The provisional prevalence of the disease ranged between 0 - $84 \%$ nationwide (Bishop, 2017).

Previous studies revealed that both urinary and intestinal schistosomiasis is prevalent among school aged children in Dutse (Ahmed et al., 2015, Bashir et al., 2016). Preliminary investigation on freshwater snail vectors of Warwade dam located close to the village revealed the presence of Bulinus globosus and Lymnaea natalensis known to transmit schistosomiasis and fascioliasis respectively (Dogara et al., 2019).The same investigation reported that members of the Warwade community were engaged in anthropogenic activities such as farming, fishing, washing of clothes and swimming that exposes them to schistosomiasis infection. Current literature revealed that there is no documented information on the extent and nature of community transmission of schistosomiasis in Warwade village that is required for planning and executing an effective schistosomiasis control programme. This study was planned and designed to provide this much needed information.

\section{MATERIALS AND METHODS}

\section{Study Area}

Figure 2, shows Warwade village, situated in Dutse Local Government Area, Jigawa State with geographical coordinates of $11^{\circ} 45^{\prime} 0^{\prime \prime}$ North, $9^{\circ} 13^{\prime} 0^{\prime \prime}$ East. Warwade village is about 15 $\mathrm{km}$ south of Dutse (Rilwanu, 2018). Warwade is a community of settled and semi-settled Hausa/Fulani tribes whose occupation are mainly farming, cattle rearing and fishing. The community has a population of 1,500 people living in the community (Rilwanu, 2018). 


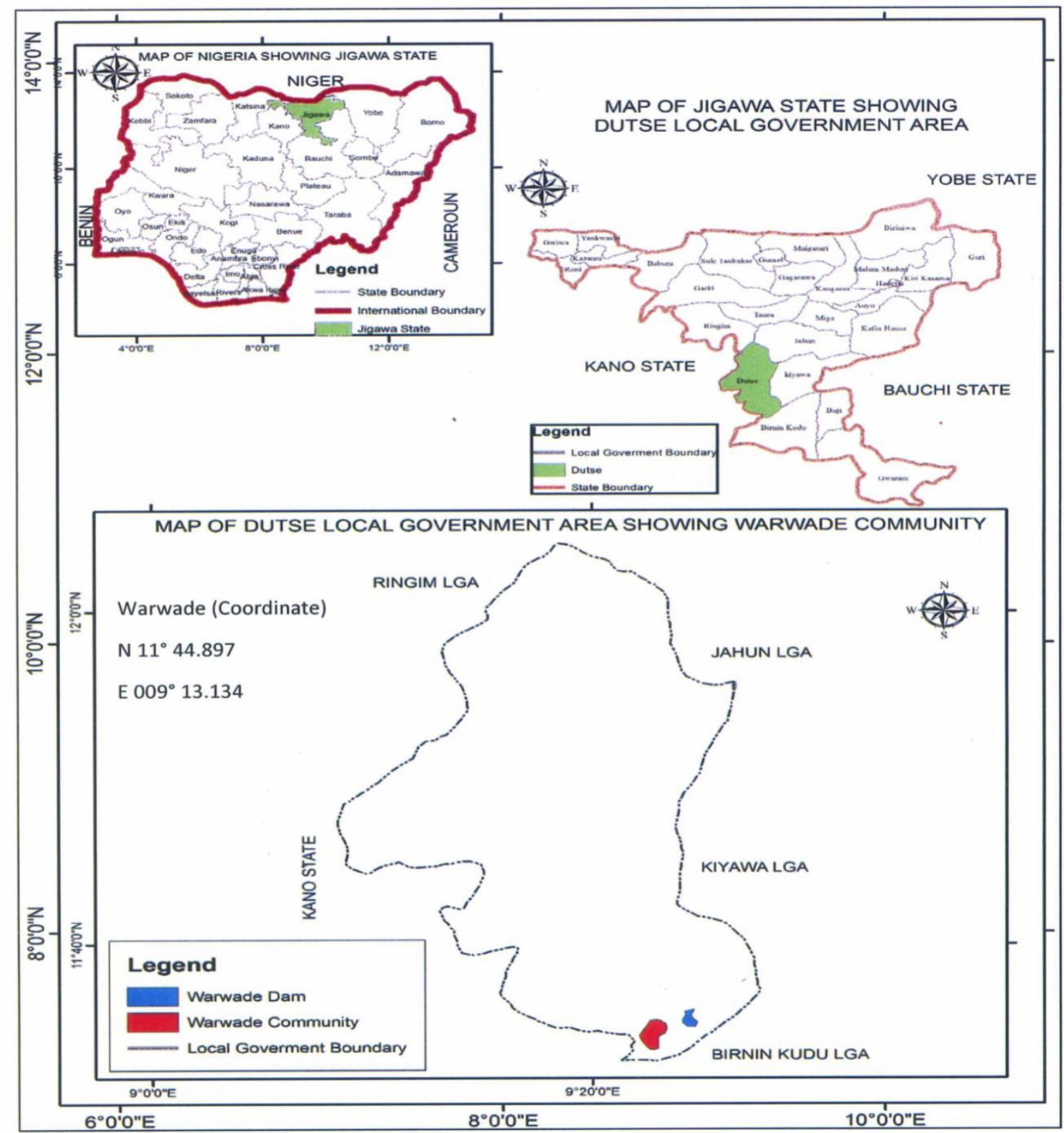

(Source: Google Earth, 2019)

Fig 2: Map of the Study Area

\section{Study Population}

The population for the study consisted of 300 randomly selected individuals representing all age grouns and sexes from the communitv. The sample size was determined using the formula Figure 1: Map of the study area

\section{Specimen Collection and Processing}

Advocacy visit to traditional head of the village and other elders living in the community was done prior to sample collection. This was preceded by sensitization session where members of the community were informed out the research work and volunteers were sought from the community. This activity took place near the Central Mosque of the village. One hundred and fifty houses from all the hamlets in the community were randomly selected. From each house two participants were selected making up the sample size of 300 . 
After obtaining informed consent of the participants and in the case of minors from their parents or guardians, each of the volunteer was given instruction on how to collect the stool and urine samples. They were then given two labeled sterile specimen screwed cap bottles in which they collected the samples (about10mls of urine and $5 \mathrm{gm}$ of stool) between 7:00am and 10:00am as described by (Lucas and Gilles, 1990). The samples were transported in ice container to the Biology Laboratory, Federal University Dutse where they were processed immediately. The urine samples were processed using sedimentation technique as described by Dazo and Biles (1974). The supernatant was discarded using syringe and needle, and the sediment was transferred to a plain slide with cover slip and the sediment was examined under $\times 40$ magnification of the light microscope. Eggs were detected and identified by the shape and terminal spine characteristic of S. haematobium. The stool samples were analyzed as outlined by (Feldmeir and Proggens, 1993) using Kato-katz kit.

Malachite green was added to each of the processed slide and was examined under the microscope initially under $\times 10$ and later $\times 40$ for the presence of egg or ova of $S$. mansoni. The eggs were detected and identified by the shape and lateral spine characteristics of $S$. mansoni. Positive samples were counted and recorded.

The urine samples of individuals that tested positive were collected and subjected to molecular detection of $S$. haematobium. The samples were used to recover ova of $S$. haematobium through sedimentation method as described by (Dazo and Biles, 1974). The ova were subjected to DNA extraction and PCR analysis.

\section{Administration of Questionnaire}

A pretested structured questionnaire was administered to the three hundred participants (in the case of minors their parents/guardians) to obtain demographic and socioeconomic information such as age, gender, and other risk posing habits associated with schistosomiasis. The administration of the questionnaire was done in the local language, Hausa.

\section{Data Analysis}

The data generated were analyzed using Statistical Package for the Social Sciences version 25. Prevalence of schistosomiasis was calculated and expressed in percentages. Chi square was used to find any significant difference between prevalence of schistosomiasis and factors such as gender, age, frequency of water contact, water contact activity and source of drinking water. Pearson Moment of Correlation was also calculated to determine the association between schistosomiasis infection and risk factors. The level of significance was determined at $\mathrm{P}<0.05$ and $95 \%$ confidence interval.

\section{Ethical Consideration}

Ethics Committee, Federal University Dutse approved the research. Permission to conduct the study in Warwade community was also obtained from Jigawa State Ministry of Health. The purpose of the study was explained to the village head and ward heads of the community of Warwade village while informed consent of all the participants was sought in writing (in case of minors it was obtained from their parents or guardians).

\section{RESULTS}

\section{Socio-demographic Characteristics and Potential Risk Factors}

Table 1 presents the demographic characteristics of the participants. The study participants were mainly composed of males (64.3\%). The age ranged between 3 and 78 years, with a mean \pm SD of $30.2 \pm 13.9$ years, and a median of 30 years. Majority of the participants belonged to 30 to 39 year age group (31\%), closely followed by those 18 to 29 years $(29 \%)$ 
and 40 and above $(22.3 \%)$. Children $<18$ years accounted for $17.7 \%$ of the study participants. Most participants came in contact with water body within the community on a daily basis (n $=166,55.3 \%)$ and weekly $(\mathrm{n}=120,40 \%)$, with washing accounting for $43.3 \%$ of water contact activities in the communities, followed by farming and irrigation (23.7\%). Ninety percent of members of the community source their drinking water from wells

Table 1: Socio-demographic of study participants and potential risk factors

\begin{tabular}{|c|c|c|}
\hline Variables & $\begin{array}{l}\text { Frequency } \\
\text { (n) }\end{array}$ & $\begin{array}{r}\text { Proportion } \\
(\%)\end{array}$ \\
\hline \multicolumn{3}{|l|}{ Gender } \\
\hline Female & 107 & 35.7 \\
\hline Male & 193 & 64.3 \\
\hline \multicolumn{3}{|l|}{ Age groups } \\
\hline$<18$ years & 53 & 17.7 \\
\hline 19 to 29 years & 87 & 29.0 \\
\hline 30 to 39 years & 93 & 31.0 \\
\hline$\geq 40$ years & 67 & 22.3 \\
\hline Age range & 3 to & \\
\hline Mean \pm SD age & 30.2 & \\
\hline Median age & $30 y$ & \\
\hline \multicolumn{3}{|l|}{ Frequency of water contact } \\
\hline None & 8 & 2.7 \\
\hline Daily & 166 & 55.3 \\
\hline Weekly & 120 & 40.0 \\
\hline Monthly & 6 & 2.0 \\
\hline \multicolumn{3}{|l|}{ Water contact activities } \\
\hline None & 8 & 2.7 \\
\hline Bathing & 11.7 & \\
\hline Fishing & 28 & 9.3 \\
\hline Farming/Irrigation & 71 & 23.7 \\
\hline Swimming & 28 & 9.3 \\
\hline Washing & 130 & 43.3 \\
\hline \multicolumn{3}{|l|}{ Source of drinking water } \\
\hline Well & 270 & 90.0 \\
\hline Dam & 30 & 10.0 \\
\hline
\end{tabular}

\section{Prevalence of Schistosoma Infection}

Out of 300 individuals examined, 61 persons were positive for schistosomiasis (urinary and intestinal) and the overall prevalence in the community was 20.3\% (95\% CI: 15.9 to $24.9 \%)$. The overall prevalence also revealed that females had slightly higher prevalence than males. The age group $>40$ years had higher prevalence than the combined prevalence of $21.43 \%$ found among children less than 18 years and $18-29$ years. The prevalence of urinary and intestinal schistosomiasis was $12.3 \%$ (95\% CI: 8.8 to $16.2 \%$ ) and 8\% (95\% CI: 5.4 to $11.6 \%$ ) respectively. The results as shown in Table 2 suggested that 1 in every 8 persons in the community had urinary schistosomiasis, 1 in 12 intestinal while 1 in 5 was infected by at least one of the two types. 
Figure 2 presents the prevalence of the disease according to age and sex. The prevalence of urinary schistosomiasis was more in females, while in the intestinal infection it was higher in males. With regards to age groups, prevalence of urinary schistosomiasis was highest among children less than 18 years $(22.6 \%)$ and individuals 40 years and above $(20.9 \%)$. The

12

\section{9 to 29 yrs $-5.7 \%$}

10

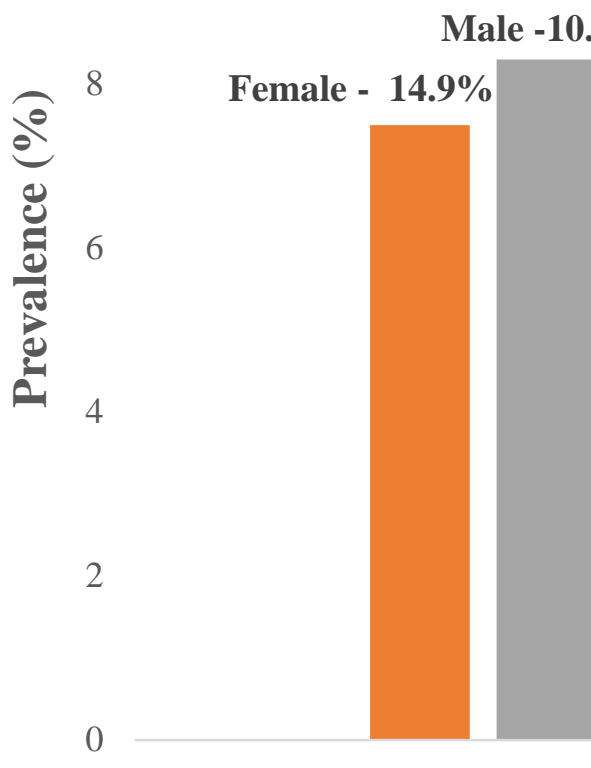

Gender

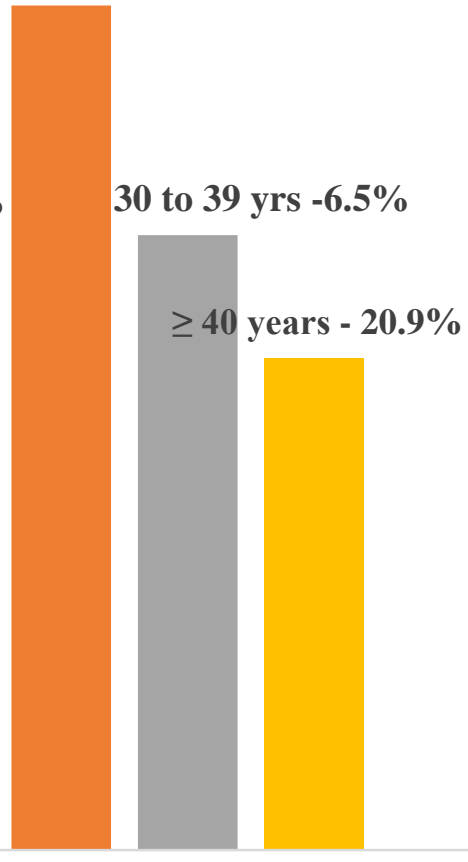

Intestinal

Examined
Age

$<18$ yrs $-22.6 \%$

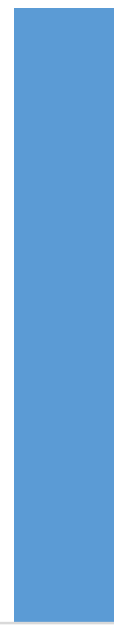

30 to 39 yrs $-6.5 \%$

ears $-20.9 \%$

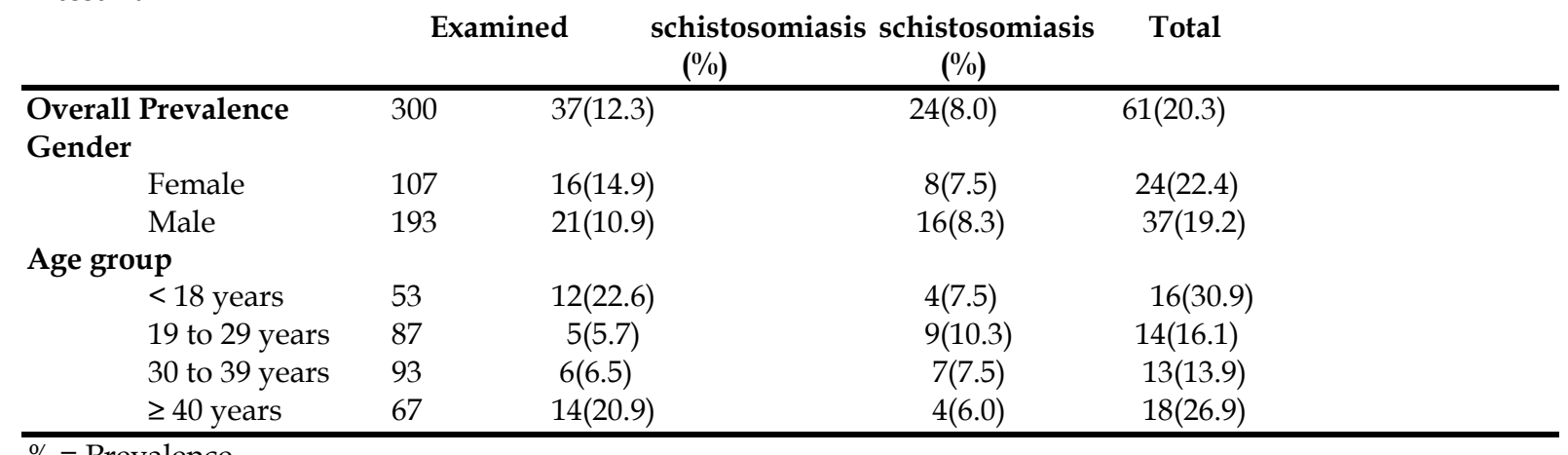

$\%=$ Prevalence 
Figure 2: Prevalence of urinary schistosomiasis in Warwade community by gender and age

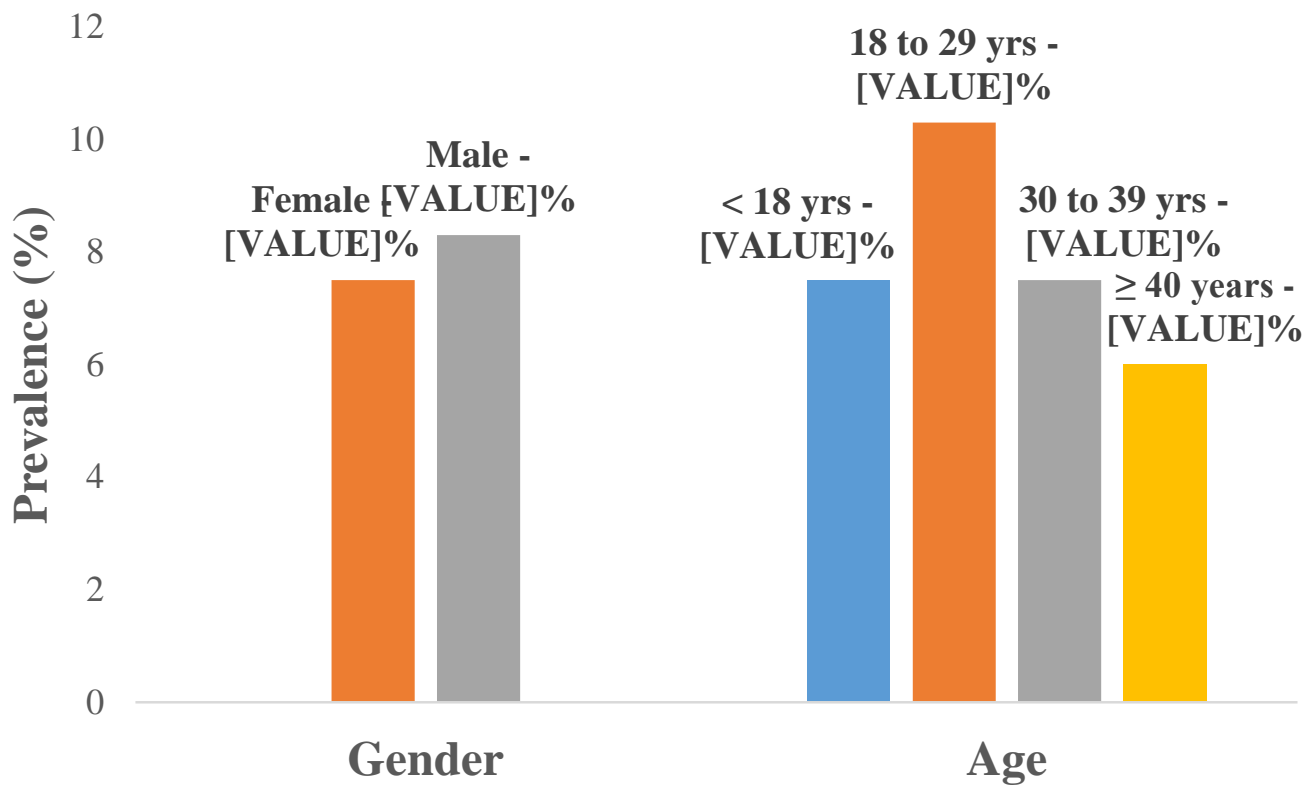

Higure $\quad 3$ :

of Intestinal schistosomiasis according to gender and age in Warwade community

Prevalence

\section{Risk factors associated with schistosomiasis}

In Table 3, gender, age, occupation, source of drinking water, water contact activities and its frequency were examined for their significance as risk factors associated with schistosomiasis. Age and occupation were statistically significant factors associated with Schistosoma infection in Warwade community. The results suggested that children less than 18 years old and older adults (40 years and above) were more prone to Schistosoma infections and the infections were highest amongst children less than 18 years.

Table 3: Bivariate analysis of risk factors associated with overall prevalence of schistosomiasis in Warwade community $(n=300)$

\begin{tabular}{|c|c|c|c|c|c|c|}
\hline \multirow[t]{2}{*}{ Factors } & \multicolumn{2}{|c|}{ NO. Positive cases } & \multirow[t]{2}{*}{$X^{2}$} & & \multirow{2}{*}{\multicolumn{2}{|c|}{$P$-value }} \\
\hline & Examined & NO. $(\%)$ & & & & \\
\hline Gender & & & & 0.11 & & 0.74 \\
\hline Female & 107 & $24(22.5)$ & & & & \\
\hline Male & 193 & $37(19.2)$ & & & & \\
\hline Age groups & & & & 8.91 & & $0.03^{*}$ \\
\hline$<18$ years & 53 & $16(30.2)$ & & & & \\
\hline 18 to 29 years & 87 & $14(16.1)$ & & & & \\
\hline 30 to 39 years & 93 & $13(14.0)$ & & & & \\
\hline$\geq 40$ years & 67 & $18(26.9)$ & & & & \\
\hline Occupation & & & & 10.6 & & $0.03^{*}$ \\
\hline Dependents & 70 & $23(32.9)$ & & & & \\
\hline Housewife & 82 & $13(15.9)$ & & & & \\
\hline Traders/Business & 28 & $7(25.0)$ & & & & \\
\hline Farming/Irrigation & 86 & $14(16.3)$ & & & & \\
\hline Fishing & 34 & $4(11.8)$ & & & & \\
\hline Frequency of water contact & & & 1.22 & & 0.27 & \\
\hline Non frequent users & 134 & 23(17.2) & & & & \\
\hline Frequent users & 166 & $38(22.9)$ & & & & \\
\hline Water contact activities & & & 2.58 & & $N A$ & \\
\hline None & 8 & $0(0.0)$ & & & & \\
\hline
\end{tabular}




\begin{tabular}{cccc} 
Domestic & 193 & $42(21.8)$ & \\
Occupational & 99 & $19(19.2)$ & 2.08 \\
Source of drinking water & & & \\
Well & 270 & $52(19.3)$ & \\
Dam & 21 & $9(42.9)$ \\
\hline *Significant at $P<0.05$ & \%=Prevalence & NA=Not Applicable
\end{tabular}

\section{Molecular detection of urinary schistosomes}

The thirty seven urine samples found positive for urinary schistosomiasis subjected to PCR amplification were confirmed positive for S. haematobium infections as shown in Plates I, II and III.

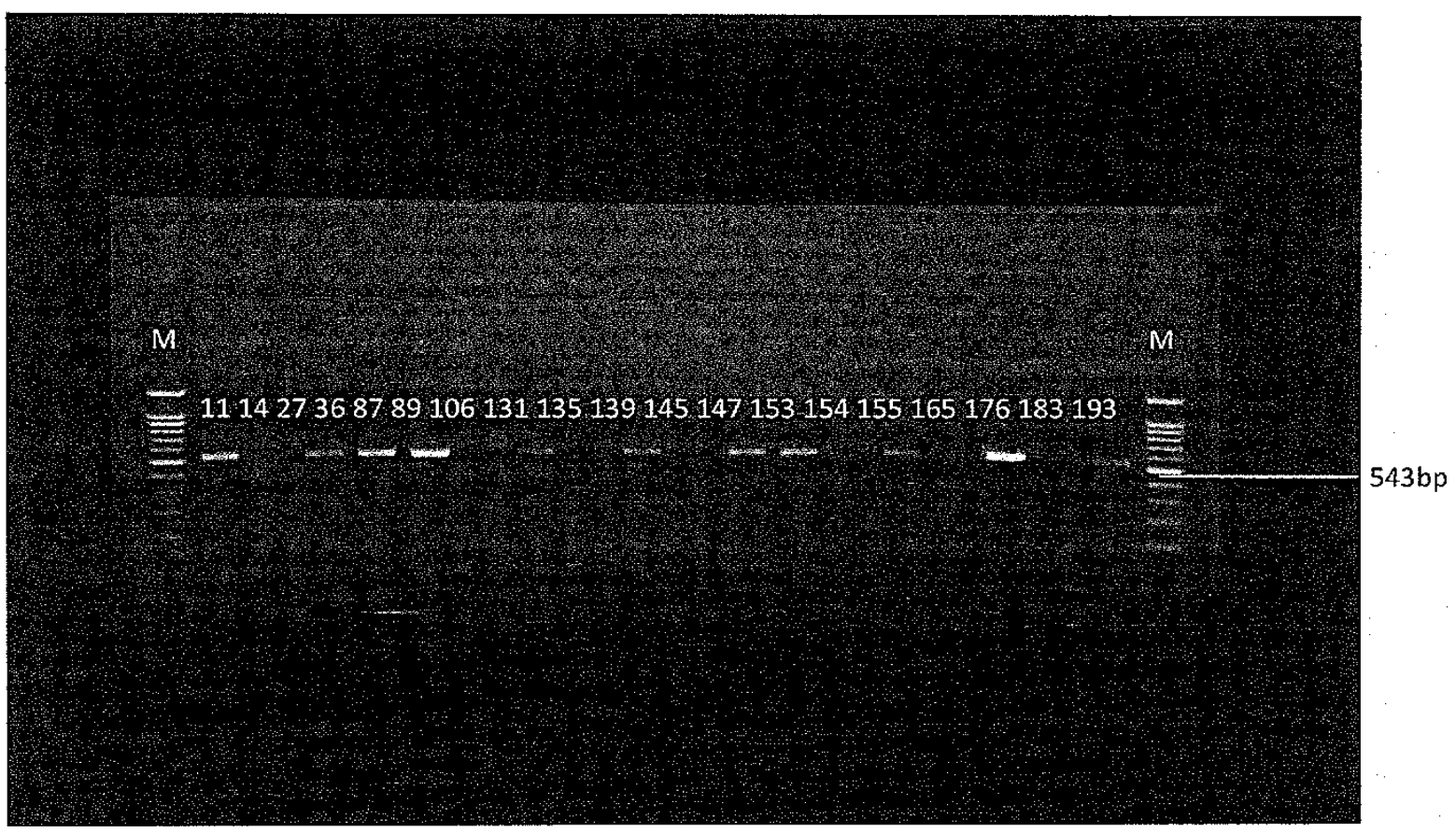

Plate I: PCR (Gel Electrophoresis) of the urine samples

$\mathrm{M}=$ Mass Spectrometry

Legend

Positive sample

Base pairs 


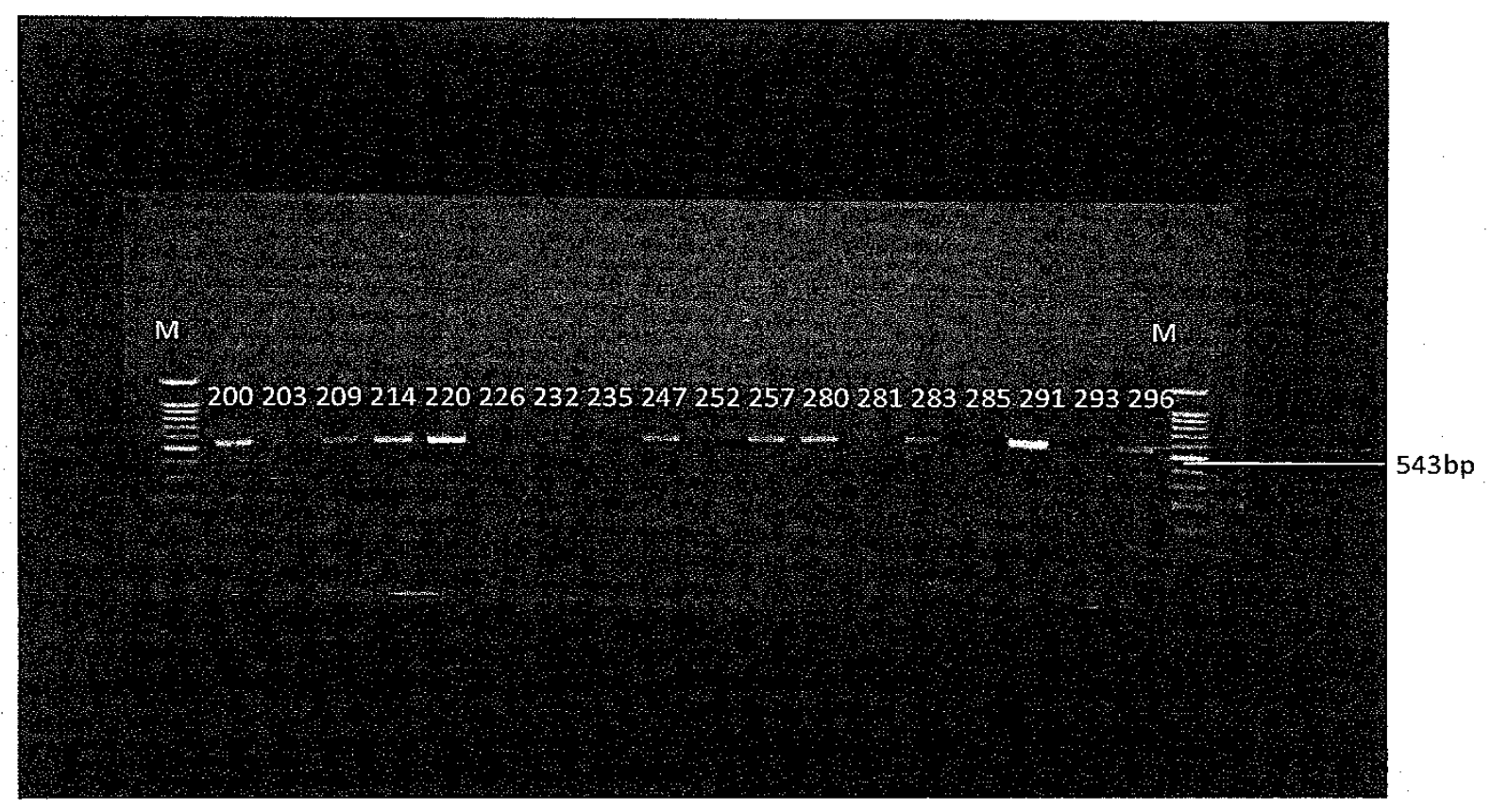

Plate II: PCR (Gel Electrophoresis) of the urine samples $M=$ Mass Spectrometry

Legend

Positive sample

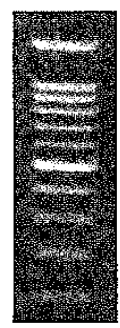

Base pairs 


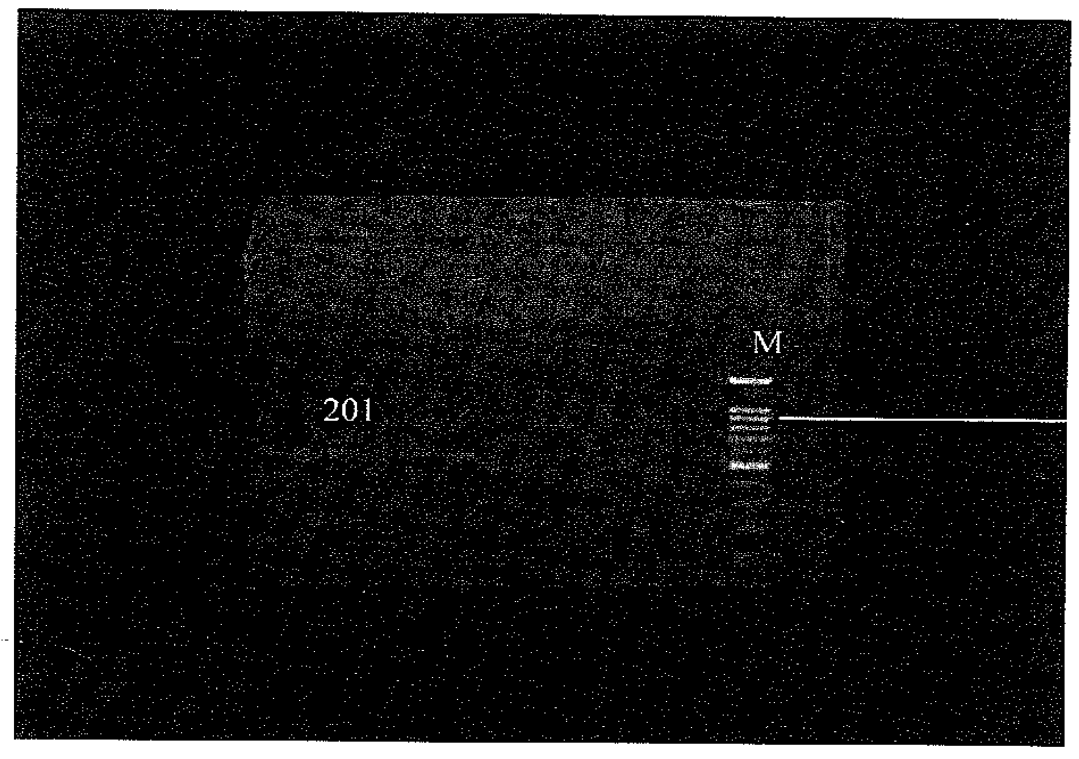

$543 \mathrm{bp}$

Plate III: PCR (Gel Electrophoresis) of the urine samples

$\mathrm{M}=$ Mass Spectrometry

Legend

Negative sample

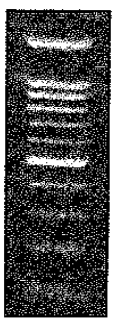

Base pairs 


\section{DISCUSSION}

This study revealed that schistosomiasis is endemic in Warwade community, but the level of endemicity according to Ezeh et al. (2019) was moderate as it falls within the range of $10 \%$ to $50 \%$. The prevalence was comparable to previous findings by Ahmed et al., (2015) and Bashir et al., (2016) from the same locality and that reported by Omenesa et al. (2015) in Bomo, Zaria, Kaduna State and by Adulugba et al. (2015) in Agatu communities, Benue State. However, the findings deferred with the work of Nanvya et al. (2011) in Ndinjor district, Lantang North, Plateau State where the disease was hyper-endemic with a prevalence of 55.7\% and that of Amutu et al. (2014) in Riverine areas of Ondo State, Nigeria, with $48.8 \%$.

The low endemicity in Warwade community may be as a result of the government intervention of mass drug administration (MDA) from 2009 to 2013 in Dutse local government area. The observed prevalence is similar to some previous reports in communities near dam sites in Nigeria where the prevalence were reported to be lower than in communities living close to streams, rivers and extensive irrigation schemes. For instance, out of the 44 Local Government Areas of Kano State, Kura with an extensive irrigation scheme had the highest prevalence (Abdullahi et al., 2011). Moreover, this study found 1 in every 5 persons was likely to be infected with either urinary or intestinal schistosomiasis further showed that the level of endemicity was moderate.

In this study prevalence of urinary schistosomiasis was more in females than males is contrary to observed norm in this part of the country where males are more engaged in activities that expose them to infection with schistosomiasis than their females counter parts. This could be because females in this community were made to engage in water contact activities such as fetching water, washing of cooking wares and clothes especially at the dam site more than the males. This probably exposed them more to infection with schistosomiasis when compared to males. Slightly higher prevalence were reported by Mbata et al. (2009), males $23.1 \%$ vs. females $22.5 \%$ and Hassan et al. (2015) 51.7\% in males and $50.5 \%$ in females. Nevertheless, much higher prevalence was observed in males than in females by (24), $67.2 \%$ vs. $44.2 \%$, (6), $60.2 \%$ vs. $47.7 \%$ and (8) $61.9 \%$ vs. $47.3 \%$. However, equal prevalence of $4.8 \%$ was reported in both sexes (Akinwale et al., 2009). These observed differences may due to variation in factors such as cultural practices and water contact behaviour among the two gender groups in different communities.

In case of intestinal schistosomiasis, our finding showed that males had higher prevalence than females. However, this observation did not agree with the work of Nanvya et al. (2011)) that reported higher prevalence in females, $18.4 \%$ than in males $10.5 \%$. The varied prevalence regarding gender may point to the species virulence rather than behavioral factor.

This work reported higher prevalence of both urinary and intestinal schistosomiasis among children and adolescents than the middle age groups. The major reason is that children and adolescents are in their active ages and were therefore more likely to have regular contact with water bodies such as that of Warwade dam that expose them to infection with schistosomiasis than older age groups. This finding is similar to the work of Kabatereine et al. (2013) who reported that children are more at risk of infection, which increases and peak between the age of 11 and 20 years old. The relatively high prevalence recorded among the older age groups in this study especially in case of urinary schistosomiasis may due to occupational exposure to the water body mainly through activities such as fishing and farming possibly becoming more vulnerable to infection with the disease.

Of all the risk factors considered in this investigation, only age and occupation were found to be significantly associated with schistosomiasis infection in Warwade community. This is 
because most members associated with these two risk factors had more water contact activities than others in the community. In terms of age it was the children and young adults that were most infected with schistosomiasis in the community. However, this finding is at variance with the observation Mbata et al. (2009) that neither age nor gender was not significantly associated with schistosomiasis infection. This is probably because members of the community had no restrictions in the way they were engaged in water contact activities such as swimming, bathing, fishing and fetching of water for other domestic activities. Farmers and fishermen being the second most infected with schistosomiasis constitute a sizeable number of the older age group whose occupation exposed them to infection with the disease. This is consistent with the findings that members of the community that engage in agricultural work and fishing as major water contact activity are more exposed to infection than others (Awosulu et al., 2020).

Molecular method is a gold standard for the diagnosis of most infection including schistosomiasis. The thirty seven urine samples that tested positive using sedimentation techniques were also positive based on PCR analysis. This goes to confirm that Warwade community is endemic for urinary schistosomiasis infection.

\section{CONCLUSION}

Warwade community is moderately endemic for schistosomiasis with an overall prevalence of $20.3 \%$ with the prevalence of urinary schistosomiasis higher $(12.4 \%)$ than intestinal with $(8 \%)$. Overall infection with schistosomiasis (urinary and intestinal) males had higher prevalence than females, but the opposite was the case in case of urinary schistosomiasis. Children and young adults were the most infected, but the older age groups also had slightly lower prevalence probably because they were engaged in activities such as fishing and farming that exposed them the more to infection with schistosomiasis. Only age and occupation was found to be significantly associated with infection with schistosomiasis. PCR analysis confirmed that all the samples that tested positive for urinary schistosomiasis by sedimentation method were indeed so goes support the endemicity of the disease in the community.

\section{RECOMMEDATION}

Mass chemotherapy using praziquantel should be administered on every member living in the community with exception of the sick, malnourished children and pregnant women. The use of protective wears such as boots and hand gloves by individuals that normally come into contact with water bodies especially during farming, irrigation, washing and fetching water is strongly recommended. This should be complemented with freshwater snail control in the dam and other water bodies around the community.

\section{ACKNOWLEDGEMENT}

The authors are grateful to the following: Jigawa State government for granting permission to conduct the research, the village and ward heads of Warwade village for the logistic and cooperative supports during the work, the research assistants in sample collection, the management of Federal University Dutse for providing reagents and equipment used in data collection and Mr. Gabriel for helping with data analyses.

\section{REFERENCES}

Abbasi, I., Charles, H. and Robbert, F. S. (2011). Differentiation of Schistosoma haematobium from Related Schistosome by PCR Amplifying an Inter Repeat Sequence. American Journal of Tropical Medical Hygiene, 79: 590-595. 
Abdullahi, M. K., Bassey, S. E. and Oyeyi, T. I. (2011). Epidemiology of Schistosoma haematobium in the 44 Local Government Areas of Kano State, Nigeria. Nigerian Journal of Parasitology, Volume 36(1), 38 - 43.

Adulugba, A. O. and Omudu, E. A. (2015). Epidemiological studies on some parasitological and ecological studies of schistosomiasis in Agatu, Benue State, Nigeria. Nigerian Journal of Parasitology, Volume 36(1), 38 - 43.

Ahmed, M, M., Abubakar, M. M., Lawan, M., Shu'aibu, I. and Tijjani, A. M. (2015). Schistosomiasis among primary school aged children in Dutse, Jigawa State, Nigeria. International Journal of Biological Sciences (IJBS), Vol. 02, No. 01, P. 15-22.

Akinwale, O. P., Ajayi, M. B., Akande, D. O., Adeleke, M. A., Gyang, P. V., Adeneye, A. K., Dike, A. A. (2009). Prevalence of Schistosoma haematobium infection in a Neglected Community, South Western Nigeria. International Journal of Health Research, 2(2): 149155 (e226p45-51).

Amuta, E. U., Houmsou, S. R. and Rigal, S. B. (2014). Prevalence, Intensity of Infection and Risk Factors of Urinary Schistosomiasis in Pre-School and School Aged Children in Guma Local Government Area, Nigeria. Asian Pacific Journal of Tropical Medicine, 16: $414-423$.

Aroye, M. O. (2004). Research Methodology with Statistics for Health and Social Sciences. Nigeria: Nathad Ex-Publishers, 115 - 120.

Awosolu, O. B., Yahaya, Z., Shariman, F., Haziqah, M. T. and Olusi, T. A. (2020 ). Will Nigerians Win the War Against Urinary Schistosomiasis? Prevalence, Intensity, Risk Factors and Knowledge Assessment among Some Rural Communities in Southwestern Nigeria. Pathogens, 9,128.

Bashir, S. F., Usman, U., Sani, N. M. and Kawo, A. H. (2016). Prevalence of Schistosoma haematobium among Population Aged 1-25 Years Attending Rasheed Shekoni Specialist Hospital, Dutse, Jigawa State, Nigeria. IOSR Journal of Pharmacy and Biological

Sciences (IOSR-JPBS), Volume 11, Issue 6, Ver. I (Nov-Dec.2016), PP. 20 - $24 . s$

Bishop, H. G. (2017). Menace of schistosomiasis: its true neglected nature in Nigeria. MOJ Public Health; 6(5):421-426. DOI: 10.15406/mojph.2017.06.00186.

Butterworth E. A. (1997). Schistosomiasis, epidemiology, treatment and control. Medical Group Journal of Tropical Diseases; 25(2):70-81.

Dazo, B. C. and Biles, J. E. (1974). Two New Field Techniques for Detection and Counting of Schistosoma haematobium Eggs in Urine Samples, with an Evaluation of Both Methods. Bulletin of the World Health Organisation, 51:399 - 408.

Dogara, M. M., Balogun, J. B., Muhammad, A., Abu, P., Ringim A, S., Zakaria, A. and Bashir, M. M. (2019). Abundance and Distribution of Freshwater Snails in Warwade dam, Dutse, Jigawa State Nigeria. Journal of Nigeria Tropical Biology Association, Vol. 3/19 p1-3.

Ezeh, C. O., Onyekwelu, K. C., Akinwale, O. P., Shan, L. and Wei, H. (2019). Urinary schistosomiasis in Nigeria: a 50 year review of prevalence, distribution and disease burden. Parasite, 26 : 19. doi: 10.1051/parasite/2019020.

Federal Ministry of Health (FMOH) (2015). "Nigeria master plan for Neglected Tropical Diseases (NTDs) 2015 - 2020". Government of Federal Republic of Nigeria, Abuja, 2015.http://espen.afro.who.int/system/files/content/resources/NIGERIA_NTD_M aster_Plan_2.

Feldmeir, H. and Proggense, G. (1993). Diagnosis Techniques in Schistosomiasis Control: A Review. Acta Tropicana. 52 : 205 - 207

Hassan, A. O., Amo, A. O. J., Akinwale, O. P., Deji-Agboola, A. M., Adeleke, M. A. and Gyang, P. V. (2015). Current status of urinary schistosomiasis in communities around the Erinle and Eko-Ende Dams and the implications for schistosomiasis control in 
Nigeria. Southern African Journal of Infectious Diseases ISSN: 2312-0053 (Print) 23131810 (Online) Journal homepage: https://www.tandfonline.com/loi/ojid20.

Hotez, P. J., Fenwick, A., Savioli, L. and Molyneuix, D. H. (2009). Rescuing the bottom billion through control of Neglected Tropical Diseases. Lancet; 373(9674):1570-5.

Johnsen, M. V., Bogh, H. O. and Nansen, P. (2011). Schistosoma japonicum Infection in the Pig as a Model for Human Schistosomiasis. Tropical Medical Institute of Health, 6: 163- 169.

Kabatereine, K., Takahashi, M. and Nwoke, B.E.B. (2013). Parasitological Survey in Jos, Plateau State, Nigeria. Japanese Journal of Tropical Medicine and Hygiene 14:295-302.

Kuntz, E. R. (2010). Association of Parasitic Infections Cancer. Indian Journal of Medical Microbiology, 25: 85-89.

Lucas, A. O. and Gilles, H. M. (1990). A New Short Textbooks of Preventive Medicine for the Tropic 3rd Edition. Edward Amold: Educational Low - Priced Books Scheme, Britain, Pp. 127 - 137.

Mbata, T. I., Orji, M.U. and Oguoma, V. M. (2009). High Prevalence of Urinary Schistosomiasis in a Nigerian Community. Afr. J. Biomed. Res. Vol. 12, No. 2,101 - 105.

Nanvya, T. N., Dakul, D. A. and Mwansat, G. N. (2011). Schistosomiasis in Ndinjor district of Lantang North Local Government Area of Plateau State, Nigeria. Nigerian Journal of Parasitology, Volume 32(2), 290 - 213.

Norberg, E. (2004). Communicable diseases (third edition). A manual for health workers in subsaharan Africa. Africa Medical and Research Foundation. pp.130-136.

Omenesa, H. O., Bishop, H. G. and Raji, H. M. (2015). Prevalence of urinary schistosomiasis among pupils attending primary schools in Bomo Village, Zaria, Nigeria. International Journal of Research in Engineering and Science. 3(5):14-19.

Rilwanu, Y. T. (2018). Evaluation of the status of water resources and infrastructure for community and development in Warwade, Dutse, Jigawa State, Nigeria. FUDMA Journal of Sciences, Vol. 2, No. 4, PP. 8 - 14.

Van der werf., M. J., Devlas, S. J., Brooker, S., Looman, C.W., Negel, K. and Habbema, J. D. (2013). Quantification of clinical morbidity associated with schistosoma infection in sub-saharan Africa. Acta Tropica, 86:125-139.

World Health Organization (2014). Detection of Polymerase Chain Reaction in Schistosoma mansoni DNA in Human Serum and Urine. American Journal of Tropical Medical Hygiene, 66: 157:-162.

World Health Organization (2020). Schistosomiasis. Geneva: World Health Organization. https://www.who.int/news-room/fact-sheets/detail/schistosomiasis. 